\title{
Tabagismo e controle da asma brônquica
}

Smoking and asthma control

\section{Carlos Alberto de Assis Viegas}

A dificuldade no controle da asma brônquica é um importante problema de saúde em todo o mundo e que provavelmente decorre de vários fatores; entre eles estão as mudanças ambientais e as características do estilo de vida do paciente. Consequentemente, o controle da asma é o foco central da versão atualizada do Global Initiative for Asthma Guidelines, através do qual os médicos são estimulados a se concentrar na avaliação do controle da asma, que deve ser definido pelos sintomas, pela função pulmonar e pela presença ou história de exacerbações. ${ }^{(1)}$ Da mesma forma, a epidemia de tabagismo ainda é uma preocupação de saúde pública mundial, fazendo com que o controle dos sintomas da asma em pacientes expostos à fumaça do tabaco fique ainda mais difícil. ${ }^{(2)}$

Nas últimas décadas, podemos observar importantes avanços no entendimento da fisiopatologia da asma brônquica e grande aperfeiçoamento das medicações utilizadas para seu controle. Entretanto, sabe-se que há grande variabilidade individual na resposta terapêutica, que envolve fatores genéticos e ambientais. De uma forma geral, os ensaios clínicos sobre o tratamento da asma brônquica não incluem pacientes fumantes devido ao risco de indivíduos com DPOC serem incluídos. Assim, pouco se sabe da resposta ao tratamento desse grupo específico de pacientes. ${ }^{(3)}$

Em nosso país, a dificuldade do controle da asma pode ser agravada se considerarmos que a maioria dos pacientes asmáticos não tem acompanhamento adequado, o qual muitas vezes é feito por médicos não-especialistas. Este fato acontece também em países desenvolvidos. Em uma publicação recente, com de mais de 10.000 pacientes asmáticos avaliados, foi reportado que a doença estava fora de controle em 59\% dos pacientes, bem controlada em 19\% e totalmente controlada em apenas 23\%. Além disso, o estudo indicou que pacientes mal controlados são mais frequentes entre fumantes que entre não-fumantes. ${ }^{(4)}$

No que se refere ao tabagismo, estamos observando uma diminuição importante de sua prevalência, especialmente nos países desenvolvidos. Isto se deve à implementação de políticas adequadas para seu controle, o que ainda não aconteceu na maioria dos paises em desenvolvimento. Atualmente, estima-se que cerca de $1 / 3$ da população adulta mundial seja fumante ativa e que cerca de 50\% da população total esteja exposta à fumaça de cigarro no meio ambiente, especialmente as crianças. Ainda mais grave é o fato de que, mesmo em países desenvolvidos, em torno de 30\% dos adultos com asma brônquica são fumantes habituais, os quais apresentam pior controle dos sintomas da asma quando comparados a não-fumantes. ${ }^{(5)}$

Asma e tabagismo interagem de forma importante, uma vez que o tabagismo aumenta e agrava os sintomas da asma, dificultando seu controle, assim como acelera a perda da função pulmonar e piora a qualidade de vida do paciente. Também é conhecido que o tabagismo aumenta o metabolismo da teofilina, mas principalmente, que asmáticos fumantes são menos sensíveis aos efeitos benéficos dos corticosteroides inalatórios e orais. lsto pode ser explicado pela probabilidade de que a fumaça do cigarro cause alterações na inflamação das vias aéreas observada na asma, aumentando também a hiper-responsividade brônquica. ${ }^{(2)}$ Chamamos a atenção para o fato de que fumar cigarros tem efeito negativo persistente sobre a resposta terapêutica em pacientes com asma não-controlada, mesmo após a cessação do tabagismo. ${ }^{(6)}$ Também está documentado que, em crianças, a associação de tabagismo passivo e asma tem papel fundamental no desenvolvimento e na gravidade da asma. ${ }^{(7)}$ Portanto, são muito importantes as consequências do tabagismo para a saúde pública, pois este aumenta a morbidade da asma brônquica e é o mais importante fator de risco evitável e independente para dificultar seu controle.

Nesta edição do Jornal Brasileiro de Pneumologia, Dias Jr et al. ${ }^{(8)}$ da Universidade de São Paulo, relatam os resultados de um estudo transversal aberto não-controlado, no qual voluntários asmáticos que estavam em acom- 
panhamento regular num ambulatório de asma foram avaliados quanto à prevalência de tabagismo ativo e de exposição à fumaça de cigarro. Foi surpresa o fato de que nesse grupo de asmáticos a prevalência do tabagismo foi apenas de 3\%. lsto está em desacordo com as estatísticas internacionais, nas quais a prevalência do tabagismo em pacientes com asma é aproximadamente igual à da população geral, ou seja, em cerca de 30\%. ${ }^{(5)} 0$ fato de o grupo estudado ser formado predominantemente por pacientes com asma moderada e grave pode explicar, em parte, essa baixa prevalência. Entretanto, acreditamos que isso possa também refletir o resultado das campanhas de controle do tabagismo, em franca expansão no nosso país, se consideramos a alta prevalência de ex-fumantes (33\%) encontrada no grupo. Este importante número de ex-fumantes deve ser salientado, se lembrarmos que o tabagismo é o fator evitável mais importante para a asma, dificultando o seu controle. ${ }^{(9)}$ Outro achado significativo do estudo foi a presença de exposição ambiental à fumaça do cigarro em 53\% da população avaliada. Esse dado está em total acordo com a literatura internacional, que indica que cerca de 50\% da população mundial está exposta à fumaça do tabaco, seja no ambiente doméstico, no trabalho ou durante o lazer. ${ }^{(10)}$ Esse fato reforça a necessidade ainda maior de lutarmos pela criação de ambientes livres de fumaça do tabaco, protegendo, assim, não somente os pacientes com asma, mas também toda a população não-fumante da exposição passiva à fumaça do tabaco.

Finalmente, é importante que todos nós, médicos e demais profissionais de saúde, assumamos definitivamente o tabagismo como uma doença crônica e curável (dependência de droga), que vai muito além de um mau hábito. Assim sendo, devemos abordar incessantemente todos os fumantes para que parem de fumar, fato que em nosso meio, inclusive entre pneumologistas, ainda não é feito de forma satisfatória.

\section{Carlos Alberto de Assis Viegas \\ Professor Adjunto da Faculdade de Medicina da Universidade de Brasília, Brasília, Distrito Federal}

\section{Referências}

1. Bateman ED, Hurd SS, Barnes PJ, Bousquet J, Drazen JM, FitzGerald M, et al. Global strategy for asthma management and prevention: GINA executive summary. Eur Respir J. 2008;31(1):143-78.

2. Thomson NC, Chaudhuri R, Livingston E. Asthma and cigarette smoking. Eur Respir J. 2004;24(5):822-33.

3. Thomson NC. Smokers with asthma: what are the management options? Am J Respir Crit Care Med. 2007;175(8):749-50.

4. Chapman KR, Boulet LP, Rea RM, Franssen E. Suboptimal asthma control: prevalence, detection and consequences in general practice. Eur Respir J. 2008;31(2):320-5.

5. Lazarus SC, Chinchilli VM, Rollings NJ, Boushey HA, Cherniack R, Craig TJ, et al. Smoking affects response to inhaled corticosteroids or leukotriene receptor antagonists in asthma. Am J Respir Crit Care Med. 2007;175(8):783-90.

6. Niedoszytko M, Gruchała-Niedoszytko M, Chełminska M, Sieminska A, Jassem E. Persistent impact of cigarette smoking on asthma. J Asthma. 2008;45(6):495-9.

7. Irvine L, Crombie IK, Clark RA, Slane PW, Feyerabend C, Goodman KE, et al. Advising parents of asthmatic children on passive smoking: randomised controlled trial. BMJ. 1999;318(7196):1456-9.

8. Dias Jr SA, Pinto RC, Angelini L, Fernandes FL, Cukier A, Stelmach R. Prevalência de tabagismo ativo e passivo em uma população de asmáticos. J Bras Pneumol. 2009;35(3):261-5.

9. Molimard M, Le Gros V. Impact of patient-related factors on asthma control. J Asthma. 2008;45(2):109-13.

10. Centers for Disease Control and Prevention [homepage on the Internet]. Atlanta: U.S. Department of Health And Human Services. [cited 2009 Jan 30]. Fact sheet - Trends in secondhand smoke exposure among U.S. Nonsmokers: progress and gaps (October 2006). Available from: http://www.cdc.gov/tobacco/data_statistics/fact_ sheets/secondhand_smoke/exposure/trends.htm 